\title{
Protozoários ciliados do rúmen de bovinos e bubalinos alimentados com dietas suplementadas com monensina ou própolis
}

\author{
Thaís Barros Ríspoli(1), Isabella Lopes Rodrigues(2), Rafael Gioia Martins Neto(2), Ricardo Kazama(3), \\ Odimari Pricila Pires Prado ${ }^{(3)}$, Lúcia Maria Zeoula ${ }^{(3)}$ e Pedro Braga Arcuri(4)
}

\begin{abstract}
(1)Centro de Ensino Superior de Juiz de Fora, Avenida Luz Interior no 345, Bairro Estrela Sul, Campus Arnaldo Janssen, CEP $36033-240$ Juiz de Fora, MG. E-mail: tbrispoli@yahoo.com.br (2)Universidade Federal de Juiz de Fora, Programa de Pós-Graduação em Ciências Biológicas, Comportamento e Biologia Animal, Campus Universitário, s/no, Bairro Martelos, CEP 36036-900 Juiz de Fora, MG. E-mail: rodrigues.il@hotmail.com, martinsneto@terra.com.br ${ }^{(3)}$ Universidade Estadual de Maringá, Centro de Ciências Agrárias, Departamento de Zootecnia, Avenida Colombo, no 5.790, Bairro Jardim Universitário, CEP 87020-900 Maringá, PR. E-mail: ricardokazama@gmail.com, odimari@hotmail.com, Imzeoula@uem.br (4)Embrapa Gado de Leite, Rua Eugênio do Nascimento, no 610, Bairro Dom Bosco, CEP 36038-330 Juiz de Fora, MG. E-mail: pba1@cnpgl.embrapa.br
\end{abstract}

Resumo - O objetivo deste trabalho foi avaliar o efeito de dietas suplementadas com monensina ou produtos à base de própolis, nas populações de protozoários ciliados no rúmen de bovinos (Bos taurus) e bubalinos (Bubalus bubalis). Quatro bovinos da raça Holandesa e quatro búfalos da raça Murrah adultos, fistulados no rúmen, foram distribuídos em delineamento quadrado latino (4x4). A dieta constituiu-se de $50 \%$ de silagem de milho e $50 \%$ de concentrado à base de milho em grãos e farelo de soja, com adição de monensina sódica ou aditivo à base de própolis LLOSA2 ou LLOSC1. As amostras do conteúdo ruminal foram coletadas duas horas após a alimentação. $\mathrm{O}$ gênero Entodinium foi o mais representativo em todos os tratamentos, para ambas as raças de ruminantes. Em búfalos, foi observado o efeito redutor do tratamento LLOSC1 nas populações do gênero Entodinium, além do efeito redutor dos tratamentos monensina e LLOSA2 sobre os gêneros da subfamília Diplodiniinae. A média de ciliados foi maior em bubalinos $\left(56 \times 10^{4} \mathrm{~mL}^{-1}\right)$ do que em bovinos $\left(26 \times 10^{4} \mathrm{~mL}^{-1}\right)$. Houve aumento do $\mathrm{pH}$ ruminal dos bovinos no tratamento com monensina. O extrato de própolis LLOSC1 reduziu os ciliados do rúmen em bubalinos.

Termos para indexação: Bos taurus, Bubalus bubalis, búfalo, ionóforos, microbiota ruminal, produtos LLOS.

\section{Ruminal ciliate protozoa of cattle and buffalo fed on diet supplemented with monensin or extracts from propolis}

\begin{abstract}
The aim of this work was to evaluate the effect of diets supplemented with monensin or with extracts of propolis, on the population of ciliate protozoa in the rumen of cattle (Bos taurus) and water buffalo (Bubalus bubalis). Four Holstein cattle and four Murrah buffalo, fistulated in the rumen, were distributed in $4 \times 4$ Latin square design. The diet was constituted by $50 \%$ corn silage and $50 \%$ concentrate based on corn grain and soybean meal, and the supplementation of monensin sodium or propolis extracts LLOSA2 or LLOSC1. Samples of ruminal contents were collected two hours after feeding. The genus Entodinium was the most common in all treatments for both cattle and buffalo. The LLOSC1 treatment reduced the populations of the genus Entodinium in buffalo. Monensin sodium and LLOSA2 reduced protozoa of the genera of the Diplodiniinae subfamily in buffalo. The average concentration of ciliates was higher in buffalo $\left(56 \times 10^{4} \mathrm{~mL}^{-1}\right)$ than in cattle $\left(26 \times 10^{4} \mathrm{~mL}^{-1}\right)$. There was ruminal $\mathrm{pH}$ increase in cattle treated with monensin. The LLOSC1 propolis extract reduced rumen ciliates in buffalo.
\end{abstract}

Index terms: Bos taurus, Bubalus bubalis, water buffalo, ionophores, ruminal microbiota, LLOS products.

\section{Introdução}

$\mathrm{O}$ rúmen representa um complexo ecossistema composto por microrganismos como bactérias, fungos, protozoários ciliados e flagelados. Esses microrganismos produzem enzimas capazes de degradar a celulose das plantas, o que fornece energia ao seu hospedeiro em uma relação mutualística (Arcuri et al., 2006). Os protozoários ciliados podem variar entre $10^{4}$ até $10^{6}$ ciliados por mililitro de conteúdo ruminal (Kamra, 2005).

Diversos fatores influenciam o funcionamento do ambiente ruminal, entre os quais se destacam a dieta e o pH (Nogueira Filho et al., 2001). A manipulação de dietas com aditivos tem sido foco de estudos para a diminuição da produção do gás metano, sintetizado 
pelos microrganismos do rúmen, para a melhoria do desempenho produtivo de ruminantes (DiLorenzo et al., 2006). A monensina, um antibiótico ionóforo, é um dos principais aditivos utilizados em dietas que visam ao ganho de energia pelo animal (Franzolin, 2004). Morais et al. (2006) constataram efeito negativo temporário da monensina sobre protozoários ciliados.

Em razão do risco de intoxicação e da possível resistência das bactérias, o uso de ionóforos, como a monensina, é considerado um risco crescente para a saúde humana, e os mercados consumidores têm se mostrado intolerantes aos produtos originados de animais alimentados com esse tipo de aditivo. Os órgãos oficiais e associações de consumidores da União Européia são a favor da proibição do uso desses ionóforos, por questão de prevenção (Morais et al., 2006). Em razão disso, pesquisadores têm concentrado esforços em busca de alternativas, para substituir os aditivos antibióticos na produção animal.

O própolis é um produto natural (Stradiotti Júnior et al., 2004) e tem ação antimicrobiana (Park et al., 2000). Vargas et al. (2004) ao avaliar a ação antimicrobiana da solução alcoólica do própolis a 50\%, observaram que as bactérias gram-positivas são mais sensíveis que as gram-negativas. Hino \& Russel (1987) relataram que o própolis poderia ser utilizado como aditivo nutricional, por possuir efeito tóxico sobre as populações de bactérias gram-positivas. Em estudos sobre a microbiota ruminal, Broudiscou et al. (2000) testaram a própolis e observaram que a produção de propionato aumentou em $10,3 \%$, e as populações de protozoários ciliados foram reduzidas. Entretanto, existem poucos relatos da ação do própolis sobre as populações de protozoários ciliados do rúmen.

O objetivo deste trabalho foi avaliar o efeito de dietas suplementadas com monensina ou produtos à base de própolis LLOS, nas populações de protozoários ciliados no rúmen de bovinos e bubalinos.

\section{Material e Métodos}

O experimento consistiu de duas fases: a primeira realizada no setor de bovinocultura de corte, da Fazenda Experimental de Iguatemi (FEI), e no Laboratório de Farmacotécnica da Universidade Estadual de Maringá (UEM), de 29 de setembro a 29 de dezembro de 2006; a segunda foi realizada no Laboratório de Microbiologia do Rúmen, da Embrapa
Gado de Leite, Juiz de Fora, MG, de 25 de fevereiro a 31 de março de 2008.

Foram utilizados quatro bovinos de raça Holandesa, com peso vivo médio de $400 \mathrm{~kg}$, e quatro bubalinos da raça Murrah, com peso vivo médio de $620 \mathrm{~kg}$, todos castrados e canulados ruminalmente. Os animais foram mantidos em baias individuais de $10 \mathrm{~m}^{2}$, em que metade da área era coberta com telha de zinco e, sob cada cobertura, havia um bebedouro, com capacidade para $250 \mathrm{~L}$ de água, e um comedouro com $2 \mathrm{~m}$ lineares. Foi utilizado o delineamento quadrado latino (QL) $4 \times 4$, em que cada fase compreendeu 14 dias de adaptação aos tratamentos e 7 dias de coleta.

Os tratamentos foram: dieta sem aditivos; dieta e monensina sódica (Rumensin); e dieta e aditivos à base de própolis, constituída de um núcleo para ração e extrato de própolis: LLOSA2 (álcool 2, concentração de própolis A) e LLOSC1 (álcool 1, concentração de própolis C) (Prado, 2005). Os produtos LLOSA2 e LLOSC1 foram produzidos no Laboratório de Farmacotécnica da UEM, conforme Franco \& Bueno (1999), e estão patenteados como propriedade intelectual no PI 0605768-3. As concentrações de flavonoides totais, medidas em concentrações de crisina, por análise cromatográfica (cromatografia líquida de alta eficiência), foram de $0,018 \mathrm{mg} \mathrm{g}^{-1}$ para LLOSC1 e de $0,001 \mathrm{mg} \mathrm{g}^{-1}$ para LLOSA2 (Prado, 2005). Esses produtos foram selecionados a partir de estudos in vitro previamente realizados, e entre produtos que apresentaram maior valor de digestibilidade in vitro de matéria seca (DIVMS) em dietas com $50 \%$ de volumoso e $50 \%$ de concentrado, em relação ao controle (Prado, 2005).

A ração foi formulada para conter $50 \%$ de volumoso (silagem de milho) e $50 \%$ de concentrado (milho em grãos e farelo de soja), de acordo com o National Research Council (1996). O volumoso e o concentrado foram misturados nos cochos e fornecidos aos animais duas vezes ao dia, em duas porções iguais, uma pela manhã ( $8 \mathrm{~h}$ ) e outra à tarde (16h). Os animais receberam os diferentes aditivos diretamente no rúmen, em separado da ração, no momento da alimentação, o que garantiu o fornecimento da dose diária correta. A dose diária foi de $2 \mathrm{~g}$ de aditivo, dividida em $1 \mathrm{~g}$ na alimentação matinal e $1 \mathrm{~g}$ na alimentação vespertina.

As amostras do conteúdo ruminal para verificação do pH foram coletadas no $18^{\circ}$ dia, antes da alimentação, e 2, 4, 6 e 8 horas depois do fornecimento da dieta com os tratamentos. As amostras do conteúdo ruminal 
para contagem dos ciliados foram coletadas no 19 dia do experimento, 2 horas após a alimentação. O conteúdo ruminal coletado para contagem dos protozoários ciliados foi filtrado em gaze e espremido manualmente. O líquido ruminal foi armazenado em recipientes de plástico, que foram, em seguida, vedados e identificados. As amostras foram fixadas em igual volume de formalina a $18,5 \%$, segundo Dehority (1984), com modificações de D'Agosto \& Carneiro (1999).

A identificação e a avaliação quantitativa foram realizadas em câmara de contagem Sedgewick-Rafter. Foram consideradas as médias das contagens feitas em 100 campos independentes, realizadas em duplicata. O procedimento para identificação foi baseado em Ogimoto \& Imai (1981).

Os dados foram analisados de acordo com Universidade Federal de Viçosa (2007). Os resultados foram submetidos ao teste de normalidade Lilliefors e, em seguida, foi feita a análise de variação pelo teste de Newman-Keuls, a 5\% de probabilidade.

\section{Resultados e Discussão}

Foi observada a ocorrência de ciliados no rúmen de bubalinos dos gêneros Isotricha e Dasytricha da família Isotrichidae, do gênero Entodinium da subfamília Entodiniinae e dos gêneros Diplodinium, Eodinium, Eremoplastron, Eudiplodinium, Diploplastron,
Polyplastron, Elytroplastron, Metadinium, Ostracodinium e Enoploplastron da subfamília Diplodiniinae. Em bovinos, foram registrados os mesmos gêneros de ciliados observados em bubalinos, com a ausência dos gêneros Elytroplastron $\mathrm{e}$ Eudiplodinium.

Os gêneros observados da subfamília Diplodiniinae, com exceção de Eodinium, foram analisados em conjunto e estão referidos como Diplodiniinae, por representarem menos de $5 \%$ do total de ciliados encontrados. Os gêneros Isotricha e Dasytricha foram analisados em conjunto e estão referidos como Isotrichidae, por representarem $1 \%$ do total de ciliados observados.

O gênero Entodinium foi o mais representativo em todos os tratamentos, com mínimo de $85 \%$ em bovinos e mínimo de $89 \%$ em bubalinos (Tabela 1). A predominância do gênero Entodinium coincide com as observações de Martinele et al. (2008), que investigaram ciliados em vacas Holandesas sob dieta rica em silagem de milho e concentrado com adição de monensina ou óleo de soja. Valinote et al. (2005) observaram maior população de Entoninium no rúmen de novilhos Nelore, alimentados com cana-deaçúcar e aditivo monensina. Entretanto, nos búfalos, a alta população de Entodinium e a baixa população dos Diplodiniinae (máximo de 5\%) contrariam os resultados de Franzolin \& Franzolin (2000), que observaram população de Diplodiniinae maior que de Entodinium no rúmen de búfalos, em relação aos

Tabela 1. Concentração média, erro-padrão da média (EPM) e percentual (Perc.) de Entodinium, Isotrichidae, Eodinium e Diplodiniinae (nx10 ciliados por mililitro), no rúmen de bovinos (Bov.) e bubalinos (Bub.) submetidos à dieta com suplementação de monensina ou de extrato de própolis $\operatorname{LLOS}^{(1)}$.

\begin{tabular}{|c|c|c|c|c|c|c|c|c|c|}
\hline \multirow[t]{3}{*}{ Tratamento } & \multirow[t]{3}{*}{ Variável } & \multicolumn{8}{|c|}{ Protozoários ciliados } \\
\hline & & \multicolumn{2}{|c|}{ Entodinium } & \multicolumn{2}{|c|}{ Isotrichidae } & \multicolumn{2}{|c|}{ Eodinium } & \multicolumn{2}{|c|}{ Diplodiniinae } \\
\hline & & Bov. & Bub. & Bov. & Bub. & Bov. & Bub. & Bov. & Bub. \\
\hline \multirow[t]{3}{*}{ Sem aditivos } & Média & 112,60 & $257,32 a$ & 1,40 & 1,48 & 5,48 & 9,92 & 4,08 & $8,32 \mathrm{~b}$ \\
\hline & EPM & 50,49 & 50,63 & 0,85 & 0,41 & 2,88 & 6,84 & 2,17 & 2,64 \\
\hline & Perc. & 90,81 & 0,93 & 1,13 & 0,53 & 4,42 & 3,58 & 3,29 & 3,00 \\
\hline \multirow[t]{3}{*}{ Monesina } & Média & 90,72 & $224,00 \mathrm{ab}$ & 0,96 & 1,28 & 7,84 & 4,76 & 2,20 & $4,32 \mathrm{~d}$ \\
\hline & EPM & 7,41 & 41,88 & 0,48 & 0,37 & 3,33 & 1,79 & 0,55 & 2,07 \\
\hline & Perc. & 89,19 & 95,56 & 0,94 & 0,55 & 7,71 & 2,03 & 2,16 & 1,84 \\
\hline \multirow[t]{3}{*}{$\operatorname{LLOSA}^{(2)}$} & Média & 83,90 & $188,30 \mathrm{ab}$ & 1,08 & 1,84 & 8,92 & 7,88 & 4,72 & $7,04 \mathrm{c}$ \\
\hline & EPM & 16,50 & 43,39 & 0,39 & 0,83 & 5,09 & 3,07 & 1,94 & 2,09 \\
\hline & Perc. & 85,09 & 91,84 & 1,10 & 0,90 & 9,05 & 3,84 & 4,79 & 3,43 \\
\hline \multirow[t]{3}{*}{$\operatorname{LLOSC}^{(3)}$} & Média & 169,10 & $158,32 b$ & 1,04 & 2,24 & 9,48 & 7,44 & 4,44 & $9,52 \mathrm{a}$ \\
\hline & EPM & 42,20 & 41,40 & 0,48 & 0,66 & 6,99 & 3,35 & 2,37 & 2,62 \\
\hline & Perc. & 91,90 & 89,18 & 0,57 & 1,26 & 5,15 & 4,19 & 2,41 & 5,36 \\
\hline
\end{tabular}

${ }^{(1)}$ Médias seguidas por letras iguais, nas colunas, não diferem entre si pelo teste de Newman-Keuls, a 5\% de probabilidade. ${ }^{(2)}$ Dieta e extrato de própolis LLOSA2. ${ }^{(3)}$ Dieta e extrato de própolis LLOSC1. 
bovinos sob dieta à base de cana-de-açúcar in natura. Entretanto, neste trabalho, a alta população de Entodinium e a menor população de Diplodiniinae, em búfalos, poderia ser explicada pela maior quantidade de concentrado, uma vez que os Diplodiniinae são considerados principalmente microrganismos celulolíticos (Bohatier, 1991) e, em sua maioria, a fauna ruminal tem como principal substrato os açúcares e o amido como fonte de energia (Arcuri et al., 2006).

A maioria dos trabalhos que comparam a fauna de bovinos e bubalinos sob diferentes situações alimentares, como por exemplo, dietas ricas em cana-de-açúcar (Franzolin et al., 1997; Franzolin \& Franzolin, 2000) ou dietas à base de capim (Franzolin \& Dehority, 1999), relatam população total de ciliados maior em bovinos do que em bubalinos, o que contradiz os resultados encontrados neste trabalho (Tabela 2). Contudo, bubalinos em geral parecem abrigar no rúmen uma fauna diferente dos demais ruminantes, por terem em seu habitat consumido mais alimentos fibrosos e de baixa qualidade, durante seu processo evolutivo (Franzolin, 2004).

A monensina promoveu redução numérica na maioria dos gêneros de ciliados em bovinos, mas seu efeito não foi significativo ( $>0,05)$ (Tabela 1). Como a coleta das amostras de ciliados ocorreu no $19^{\circ}$ dia da suplementação da dieta com monensina, os protozoários ciliados podemterdemonstradoresistênciaaesseaditivo. Morais et al. (2006) encontraram resultado semelhante, tendo descrito que esse efeito tóxico foi apenas temporário, pois após um período de suplementação constante da dieta com monensina, as populações de protozoários ciliados voltaram ao seu estágio inicial. Esta observação é similar à de Valinote et al. (2005) e Martinele et al. (2008), que realizaram a coleta do material a partir do $21^{\circ}$ e $15^{\circ}$ dia, respectivamente, e

Tabela 2. Concentração total de ciliados (nx104 ciliados por mililitro), no rúmen de bovinos e bubalinos submetidos à dieta com aditivos monensina ou própolis LLOS.

\begin{tabular}{llcccc}
\hline Espécie & Variável & \multicolumn{4}{c}{ Tratamento } \\
\cline { 3 - 6 } & & Sem aditivos & Monensina & LLOSA2 $^{(1)}$ & LLOSC1 $^{(2)}$ \\
\hline Bovino & Média & 123,56 & 101,72 & 98,52 & 184,06 \\
& EPM $^{(3)}$ & 51,91 & 5,81 & 17,31 & 49,03 \\
\hline Búfalo & Média $^{(4)}$ & $277,04 \mathrm{a}$ & $234,36 \mathrm{ab}$ & $205,06 \mathrm{ab}$ & $177,52 \mathrm{~b}$ \\
& EPM & 54,33 & 43,25 & 46,29 & 42,31 \\
\hline
\end{tabular}

${ }^{(1)}$ Dieta e extrato de própolis LLOSA2. ${ }^{(2)}$ Dieta e extrato de própolis LLOSC1. ${ }^{(3)}$ Erro-padrão da média. ${ }^{(4)}$ Médias seguidas por letras iguais, nas linhas, não diferem entre si pelo teste de Newman-Keuls, a 5\% de probabilidade. não encontraram alterações nas populações de ciliados, quando submetidos à dieta com monensina. A mesma resistência pode ter ocorrido com os produtos à base de própolis LLOS. No entanto, é necessário um estudo com coletas diárias e em diferentes tempos ao longo do dia para confirmação.

Os diferentes tratamentos utilizados em bovinos apresentaram diferenças estatísticas nas médias de $\mathrm{pH}$ ruminal $(F=5,6 ; p=0,034)$ (Figura 1). O aumento significativo do $\mathrm{pH}$ ruminal em bovinos, alimentados com dietas à base de silagem de milho suplementada com monensina, pode ser explicado pelo fato de este aditivo ser capaz de diminuir a produção de ácido lático, o que contribui para a elevação do $\mathrm{pH}$, conforme citado por Pereira et al. (2001). Os produtos LLOS, possivelmente, não diminuem de modo acentuado a produção de ácido lático, pois a elevação no $\mathrm{pH}$ ruminal, sob esses tratamentos, não chegou a ser tão evidente quanto no tratamento com monensina.

Em bubalinos, as populações de Entodinium sofreram redução significativa $(F=4,69 ; p=0,05)$, pelo efeito dos tratamentos (Tabela 1). Essa redução foi mais acentuada com a adição de própolis LLOSC1 à dieta, talvez por este apresentar maior concentração de própolis do que o extrato de própolis LLOSA2. No tratamento com adição de monensina, observou-se decréscimo nas populações de Entodinium. Entretanto, a redução não foi tão acentuada quanto a encontrada com a adição do extrato de própolis LLOSC1.

As populações de ciliados da subfamília Diplodiniinae, em bubalinos, diminuíram significativamente $(\mathrm{F}=4,69$; $\mathrm{p}=0,05)$ com a adição de monensina e dos extratos de própolis LLOSA2 e LLOSC1 à dieta (Tabela 1). Em razão de esses ciliados terem ocorrido em pequenas

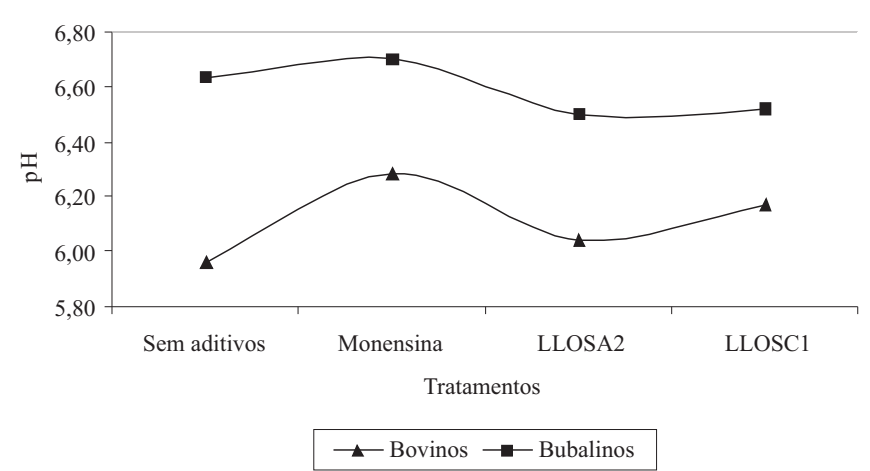

Figura 1. Médias de $\mathrm{pH}$ ruminal de bovinos e bubalinos, submetidos à dieta com adição de monensina ou de extrato de própolis LLOS. 
proporções, é complexo descrever a ação real dos tratamentos sobre cada um dos gêneros.

Em bubalinos, os valores de $\mathrm{pH}$ não foram alterados significativamente $(\mathrm{F}=1,75$ e $\mathrm{p}=0,255)$ pelo efeito dos tratamentos (Figura 1). No entanto, as médias de $\mathrm{pH}$ foram maiores do que em bovinos. Maior valor de $\mathrm{pH}$ ruminal em bubalinos também foi observado por Franzolin et al. (2002), em experimento realizado com vacas da raça Holandesa e búfalos Mediterrâneo, alimentados com feno de capim coast-cross (Cynodon dactylon) e farelo de trigo. Contudo, as médias de $\mathrm{pH}$ observadas tanto em bovinos quanto em bubalinos permaneceram dentro da faixa ótima de sobrevivência dos protozoários ciliados, segundo Williams (1986).

\section{Conclusões}

1. Os aditivos monensina e os extratos de própolis LLOSC1 e LLOSA2 têm efeito redutor nas populações de ciliados, no rúmen de bubalinos da raça Murrah.

2. O gênero Entodinium é o mais representativo, tanto no rúmen de bovinos quanto de bubalinos.

3. A população total de ciliados é maior em bubalinos do que em bovinos, independentemente da adição de monensina e de produtos LLOS à base de própolis.

\section{Agradecimentos}

À Universidade Estadual de Maringá, pela cessão dos animais; à Embrapa Gado de Leite, pela oportunidade da realização do trabalho; ao Professor Mirton Morenz, pelo auxílio nas análises estatísticas.

\section{Referências}

ARCURI, P.B.; LOPES, F.C.F.; CARNEIRO, J.C. Microbiologia do rúmen. In: BERCHIELLI, T.T.; PIRES, A.V.; OLIVEIRA, S.G de. Nutrição dos ruminantes. Jaboticabal: Funep, 2006. p.111-140.

BOHATIER, J. The rumen protozoa: taxonomy, cytology and feeding behaviour. In: JOUANY, J.P. (Ed.). Rumen microbial metabolism and ruminant digestion. Paris: Inra, 1991. p.27-38.

BROUDISCOU, L.P.; PAPON, Y.; BROUDISCOU, A.F. Effects of dry plant extracts on fermentation and methanogenesis in continuous culture of rumen microbes. Animal Feed Science and Technology, v.87, p.263-277, 2000.

D'AGOSTO, M.; CARNEIRO, M.E. Evaluation of lugol solution used for counting rumen ciliates. Revista Brasileira de Zoologia, v.16, p.725-729, 1999.
DEHORITY, B.A. Evaluation of subsampling and fixation procedures used for counting rumen Protozoa. Applied and Environmental Microbiology, v.48, p.182-185, 1984.

DiLORENZO, N.; DIEZ-GONZALES, F.; DiCOSTANZO, A. Effects of feeding polyclonal antibody preparations on ruminal bacterial populations and ruminal $\mathrm{pH}$ of steers fed high-grain diets. Journal of Animal Science, v.84, p.2178-2185, 2006.

FRANCO, S.L.; BUENO, J.H.F. Otimização de processo extrativo de própolis. Infarma, v.11, p.48-51, 1999.

FRANZOLIN, M.H.T.; SILVEIRA, A.C.; FRANZOLIN, R. Efeitos de dietas com diferentes níveis de fibra em detergente neutro e do tamanho de poros de sacos de náilon incubados no rúmen sobre a fauna ruminal em bubalinos e bovinos. Revista Brasileira de Zootecnia, v.31, p.716-723, 2002.

FRANZOLIN, R. A importância da nutrição de búfalos. Boletim do Búfalo, v.1, p.36-37, 2004.

FRANZOLIN, R.; COSTAR.M.;FRANZOLIN, M.H.T.; NOGUEIRA FILHO, J.C.M.; SCHALCH, E. Avaliação da fauna e degradabilidade no rúmen de búfalos sob dietas exclusivas de silagem de sorgo e de feno de alfafa. Arquivo Brasileiro de Medicina Veterinária e Zootecnia, v.49, p.709-718, 1997.

FRANZOLIN, R.; DEHORITY, B.A. Comparison of protozoal populations and digestion rates between watter buffalo and cattle fed an all forage diet. Journal of Applied Animal Research, v.16, p.33-46, 1999.

FRANZOLIN, R.; FRANZOLIN, M.H.T. População de protozoários ciliados e degradabilidade ruminal em búfalos e bovinos zebuínos sob dieta à base de cana-de-açúcar. Revista Brasileira de Zootecnia, v.29, p.1853-1861, 2000.

HINO, T.; RUSSEL, J.B. Relative contribution of ruminal bacteria and protozoa to the degradation of protein in vitro. Journal of Animal Science, v.64, p.261-270, 1987.

KAMRA, D.N. Rumen microbial ecosystem. Current Science, v.89, p.124-135, 2005.

MARTINELE, I.; EIFERT, E. da C.; LANA, R. de P.; ARCURI, P.B.; D`AGOSTO, M. Efeito da monensina e do óleo de soja sobre os protozoários ciliados do rúmen e correlação dos protozoários com parâmetros da fermentação ruminal e digestivos. Revista Brasileira de Zootecnia, v.37, p.1129-1136, 2008.

MORAIS, J.A.S.; BERCHIELLI, T.T.; REIS, R.A. Aditivos. In: BERCHIELLI, T.T.; PIRES, A.V.; OLIVEIRA, S.G. Nutrição de ruminantes. Jaboticabal: Funep, 2006. 583p.

NATIONAL RESEARCH COUNCIL. Nutrient requirements of beef cattle. $7^{\text {th }}$ ed. Washington, DC, 1996. 242p.

NOGUEIRA FILHO, J.C.M.; MARTIN-ORÚE, S.M.; BALCELLS, J.; FONDEVILA, M.; ABLAS, D. de S. Níveis de proteína degradável para novilhas em crescimento sobre a concentração de protozoários ciliados e outros parâmetros ruminais. Acta Scientiarum. Animal Sciences, v.23, p.945-951, 2001.

OGIMOTO, K.; IMAI, S. Atlas of rumen microbiology. Tokyo: Japan Scientific Societies Press, 1981. 231p.

PARK, Y.K.; IKEGAKI, M.; ALENCAR, S.M. de. Classificação da própolis brasileira a partir de suas características físico-químicas e propriedades biológicas. Mensagem Doce, v.58, p.2-7, 2000. 
PEREIRA, E.S.; QUEIROZ, A.C. de; PAULINO, M.F.; CECON, P.R.; VALADARES FILHO, S. de C.; MIRANDA, L.F.; ARRUDA, A.M.V. de; FERNANDES, A.M.; CABRAL, L. da S. Fontes nitrogenadas e uso de Saccharomyces cerevisiae em dietas à base de cana-de-acúcar para novilhos: consumo, digestibilidade, balanço nitrogenado e parâmetros ruminais. Revista Brasileira de Zootecnia, v.30, p.563-572, 2001.

PRADO, O.P.P. Produto à base de própolis na nutrição de ruminantes (LLOS). 2005. 78p. Dissertação (Mestrado) Universidade Estadual de Maringá, Maringá.

UNIVERSIDADE FEDERAL DE VIÇOSA. Sistemas para análises estatísticas: manual de instruções. Versão 9.1. Viçosa: UFV, 2007. 142p.

STRADIOTTI JÚNIOR, D.; QUEIROZ, A.C.; LANA, R.P.; PACHECO, C.G.; EIFERT, E.C.; NUNES, P.M.M. Ação da própolis sobre a desaminação de aminoácidos e a fermentação ruminal. Revista Brasileira de Zootecnia, v.33, p.1086-1092, 2004.

VALINOTE, A.C.; NOGUEIRA FILHO, J.C.M.; LEME, P.R.; SILVA, S.L.; CUNHA, J.A. Fontes de lipídeos e monensina na alimentação de novilhos Nelore e sua relação com a população de protozoários ciliados do rúmen. Revista Brasileira de Zootecnia, v.34, p.1418-1423, 2005.

VARGAS, A.C. de; LOGUERCIO, A.P.; WITT, N.M.; COSTA, M.M. da; SILVA, M.S. e; VIANA, L.R. Atividade antimicrobiana in vitro de extrato alcoólico de própolis. Ciência Rural, v.34, p.159-163, 2004.

WILLIAMS,A.G. Rumen holotrich ciliate protozoa. Microbiological Reviews, v.50, p.25-49, 1986.

Recebido em 15 de outubro de 2008 e aprovado em 30 de dezembro de 2008 